\title{
CADEIA DE VALORES NA GESTÃO DE CUSTOS: UMA ANÁLISE ESTRATÉGICA EM COOPERATIVAS AGROPECUÁRIAS PARANAENSES
}

\section{RESUMO}

O objetivo do presente estudo é analisar sob o contexto estratégico a cadeia de valores na gestão de custos em cooperativas agropecuárias do Estado do Paraná. A contribuição ao estado da arte do tema é direcionada a exploração da literatura elaborada por diferenciados autores relacionados. A análise estratégico-competitiva busca identificar quais itens compõem a cadeia de valores das organizações e suas influências na execução, planejamento e controle de seus custos. A metodologia utilizada foi caracterizada como um estudo empírico-analítico, realizado por meio de pesquisa survey, de coleta, observação e análise dos dados. A escolha da amostra para envio dos questionários, direcionou-se à representatividade do setor agropecuário na economia paranaense e brasileira. Considerando as limitações da pesquisa, pôde-se constatar que a ligação entre as diferentes atividades das cooperativas agropecuárias, inicia-se na aquisição das matérias-primas, até a manutenção pós-vendas dos produtos por elas desenvolvidos. Com isso, as diferentes estratégias na gestão de custos dessas empresas, se consideradas na análise estratégica dos custos podem resultar na vantagem competitiva de mercado.

Palavras-chave: Cadeia de Valores; Estratégia Competitiva; Gestão de Custos.

\section{CHAIN OF VALUES IN COST MANAGEMENT: A STRATEGIC ANALYSIS IN AGRICULTURAL COOPERATIVE PARANÁ, BRAZIL}

\begin{abstract}
The aim of this study is to analyze the strategic context in the value chain cost management in agricultural cooperatives in the state of Paraná. The contribution to the state of the art theme is directed exploration of the literature produced by different authors related. The strategic and competitive analysis seeks to identify which items make up the value chain of organizations and their influences on the execution, planning and control your costs. The methodology was characterized as an empirical-analytic study conducted by survey research, collection, observation and data analysis. The choice of the sample for sending questionnaires directed to the representative of the agricultural sector in Paraná and Brazil's economy. Considering the limitations of the research, it was noted that the link between the different activities of agricultural cooperatives, begins in the acquisition of raw materials to after-sales of products developed by them. Thus, the different strategies on cost management of these companies, if considered in strategic cost analysis can result in competitive market advantage.
\end{abstract}

Keywords: Value Chain; Competitive Strategy; Cost Management. 


\section{CADENA DE VALORES EN GESTIÓN DE COSTOS: UN ANÁLISIS ESTRATÉGICO EN COOPERATIVA AGRÍCOLA PARANÁ}

\section{RESUMEN}

El objetivo de este estudio es analizar el contexto estratégico en la gestión de costes de la cadena de valor en las cooperativas agrícolas en el estado de Paraná. La contribución al estado del tema del arte se dirige la exploración de la literatura producida por diferentes autores relacionados. El análisis estratégico y competitivo busca identificar los elementos que componen la cadena de valor de las organizaciones y sus influencias en la ejecución, la planificación y el control de sus costos. La metodología se caracteriza por ser un estudio empírico-analítico realizado por la investigación de encuestas, recolección, la observación y el análisis de datos. La elección de la muestra para el envío de cuestionarios dirigidos a la representante del sector agrícola en la economía de Paraná y de Brasil. Teniendo en cuenta las limitaciones de la investigación, se observó que la relación entre las diferentes actividades de las cooperativas agrícolas, comienza en la adquisición de materias primas hasta la post-venta de productos elaborados por ellos. De este modo, las diferentes estrategias en la gestión de costes de estas empresas, si se considera en el análisis de costo estratégico puede resultar en ventaja en el mercado competitivo.

Palabras-clave: Cadena de Valor; Estrategia Competitiva; Gestión de Costes.

Delci Grapegia Dal Vesco ${ }^{1}$ Marcelo Resquetti Tarifa ${ }^{2}$ Vicente Pacheco ${ }^{3}$ Denis Dall'Asta ${ }^{4}$

\footnotetext{
${ }^{1}$ Doutora em Contabilidade e Administração pela Fundação Universidade Regional de Blumenau - FURB. Professor da Universidade Estadual do Oeste do Paraná - UNIOESTE. Brasil. E-mail: delcigrape@gmail.com

2 Doutorando em Desenvolvimento Regional e Agronegócio pela Universidade Estadual do Oeste do Paraná UNIOESTE. Professor do Departamento de Ciências Contábeis da Universidade Estadual de Londrina - UEL. Brasil. E-mail: marcelotarifa@hotmail.com

${ }^{3}$ Doutor em Engenharia de Produção pela Universidade Federal de Santa catarina - UFSC. Professor da Universidade Federal do Paraná - UFPR. Brasil. E-mail: vpacheco@ufpr.br

${ }^{4}$ Doutor em Engenharia de Produção pela Universidade Federal de Santa Catarina - UFSC. Professor e Coordenador do Curso de Ciências Contábeis da Universidade Estadual do Oeste do Paraná - UNIOESTE. Brasil. E-mail: denis.asta@unioeste.br
} 


\section{INTRODUÇÃO}

As organizações sofrem constantes mudanças e transformações a fim de se adaptarem ao mercado nos dias atuais. As atividades intrínsecas à organização criam uma cadeia de valores quando algo é agregado ao produto ou serviço. Para Atkinson et al (2000, p.77): "Uma sequência de atividades que cria um bem ou serviço pode ser vista como uma cadeia de valores desde que cada elo seu, [...] possa acrescentar algo, no produto $[\ldots]$ ".

A descentralização administrativa nas empresas surge com a finalidade de distribuir atividades e responsabilidades aos gestores. Criam-se os centros de responsabilidade com objetivos específicos e obrigações onde os chefes de cada divisão são responsáveis, além das decisões acerca de receitas e custos, como as decisões que envolvam investimentos para a continuidade da organização. Hansen e Mowen (2001, p.318-319) definem sete razões para a descentralização, todas vinculadas a aspectos positivos: melhor acesso à informação local, limitações cognitivas, resposta em tempo mais oportuno, focalização da gestão central, treinamento e avaliação, motivação e a competição realçada. Os autores afirmam ainda que sistemas de contabilidade por responsabilidade sempre espelham e apóiam a estrutura organizacional.

A vantagem competitiva origina-se das atividades ou centros de responsabilidade distintos executados pelas empresas, tais como: projeto, produção, marketing, distribuição, suporte ao produto, entre outras. Segundo Porter (1989, p.31), estas atividades podem contribuir para a posição dos custos e também criam uma base para a diferenciação de estratégias. Cada organização possui uma cadeia de valores específica, ou seja, a seqüência de atividades criadoras de bens ou serviços próprios.

Para Rocha e Borinelli (2006), autores como Porter defendem que para identificar e agir sobre a origem dos custos e sobre as fontes de diferenciação, deve-se analisar a cadeia de valor. As atividades são relacionadas por meio de elos, os quais podem ser definidos como as relações entre o modo como uma atividade de valor é executada e o custo ou desempenho de uma outra (PORTER, 1989).

Em um enfoque específico, a pretensão da pesquisa é responder à questão: Qual a análise estratégica de cadeia de valores na gestão dos custos para o cooperativismo agropecuário do estado do Paraná? E, para contribuir na solução da questão de pesquisa foi definido o objetivo do presente estudo: analisar estrategicamente quais os componentes da cadeia de valor são identificados pelas cooperativas agropecuárias do Estado do Paraná, bem como efetuar revisão bibliográfica acerca do tema. A escolha do universo foi direcionada ao fato da atividade ser predominante no estado e ser uma das principais fontes econômicas nacionais.

Foi pesquisada uma população de 76 cooperativas agropecuárias filiadas ao sistema OCEPAR - Sindicato e Organização das Cooperativas do Estado do Paraná, por meio de envio de questionário aos gestores. Os detalhamentos dos aspectos relativos à pesquisa são abordados no item procedimentos metodológicos. O trabalho é composto de sete seções. Após a presente introdução, aborda-se o referencial teórico, com ênfase na revisão bibliográfica sobre cadeia de valores, estratégias competitivas e gestão de custos. A seguir apresenta-se a metodologia utilizada. Na sexta seção são expostos as análises e os resultados da pesquisa, objeto do presente estudo, e na sétima seção são apresentadas as considerações finais.

\section{CADEIA DE VALORES}

Vieira et al. (2012) explicam que o processo de construção do ambiente somente poderá ser concretizado quando uma série de escolhas que dizem respeito a mercados, produtos, tecnologias, leva à construção de um ambiente específico pelas organizações. E, as empresas, de acordo com Porter (1989), podem ser consideradas como um conjunto de atividades distintas. Diante dessa afirmação e para um melhor entendimento sobre as estratégias gerenciadas pelas empresas considerou-se importante uma reflexão sobre os conceitos inerentes a atividades.

Hansen e Mowen (2001) caracterizam que a atividade “ [...] é uma unidade básica de trabalho realizada dentro de uma organização". Uma agregação de ações úteis aos gestores para fins de planejamento, controle e tomada de decisão.

Para Martins (2003, p. 93) "É uma ação que utiliza recursos humanos, materiais, tecnológicos e financeiros para se produzirem bens e serviços. É composta por tarefas necessárias ao seu desempenho". É um evento, tarefa ou unidade de trabalho com um propósito específico. Horngren, Datar e Foster (2004, p.131). As atividades subdividem-se comforme a Figura 01: 


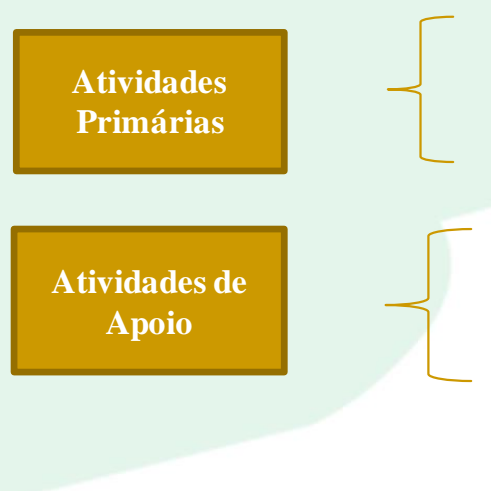

\author{
Diretamente envolvidas na: \\ Produção, entrega, comercialização ou assistência técnica ao \\ produto de uma empresa.
}

Figura 1 - Atividades organizacionais

Fonte: elaborado pelos autores

Diante da leitura de Hansen e Mowen, Martins e Horngren, Datar e Foster e principalmente de Porter, considera-se que as atividades de apoio e primárias inter-relacionadas compõem a estratégia da firma. As atividades tornam a estratégia operacional.

As atividades de apoio, podem ser exemplificadas como de infra-estrutura da companhia, gerenciamento de recursos, desenvolvimento de tecnologia as atividades primárias estão diretamente envolvidas aos produtos ou serviços ofertados pelas firmas tais como logística de entrada e saída, operações, marketing e vendas, assistência técnica.

Dentre as atividades desenvolvidas pelas empresas existem atividades que criam e geram valor, adicionam valores e as que não agregam valores. Para produção de vantagens competitivas o ideal seria que as firmas otimizassem o desenvolvimento das atividades que não agregam valor procurando eliminar os desperdícios.

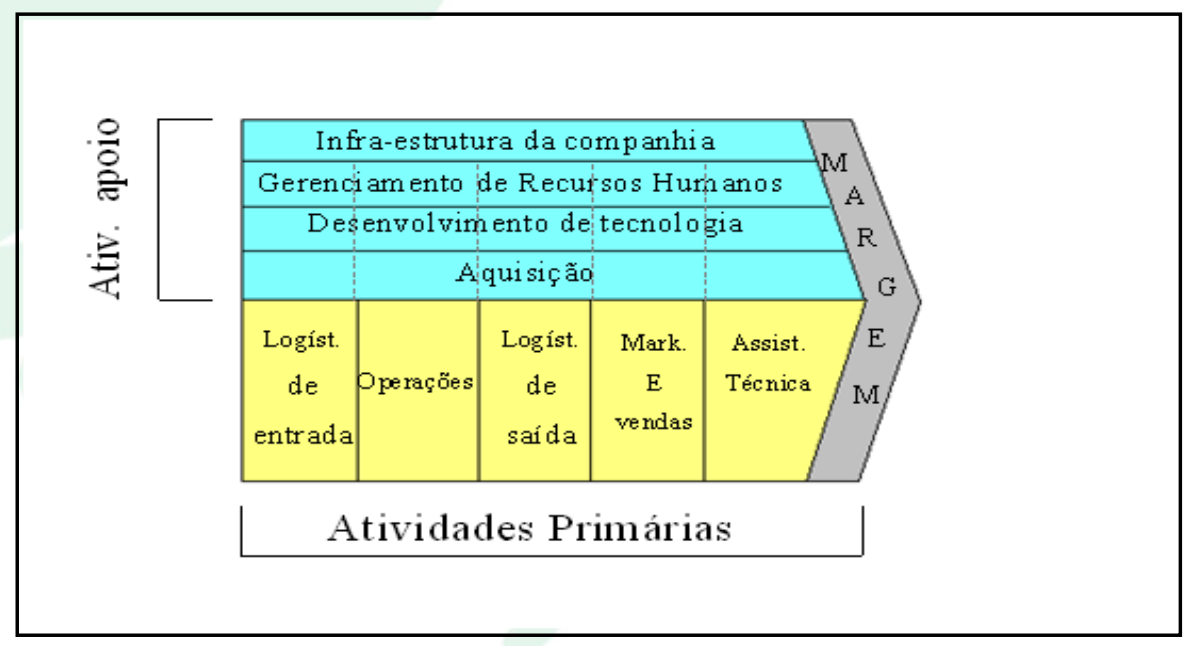

Figura 2 - Cadeia de Valores Genérica

Fonte: adaptado de Porter (1989, p.35)

Porter (1989) afirma que as atividades geram custos e criam valor para o comprador: são as unidades básicas da vantagem competitiva. A vantagem competitiva introduz o conceito de cadeia valor.

Porter (1989, p. 33) ensina que: "Toda empresa é uma reunião de atividades que são executadas para projetar, produzir, comercializar, entregar e sustentar seu produto. Todas estas atividades podem ser representadas, fazendo-se uso de uma cadeia de valores [...]" Assim faz importante também compreender qual o entendimento de cadeia de valor.

Partindo-se do pressuposto apontado por Rocha e Borinelli (2006) de que as atividades devem ser o foco da gestão para se conquistar e conservar vantagens competitivas, e sabendo-se que elas são executadas em sequência lógica, formando uma cadeia, chega-se à idéia de Cadeia de Valor

De acordo com Horngren, Datar e Foster (2004), "Cadeia de Valor é a seqüência das funções do negócio no qual a utilidade é adicionada aos produtos ou serviços de uma organização". Segundo os autores, essas funções são: Pesquisa e Desenvolvimento; Desenho; Produção; Marketing; Distribuição; Serviços ao Cliente.

Shank e Govindarajan (1997, p.14) afirmam que: 
A cadeia de valor de qualquer empresa em qualquer setor é o conjunto de atividades criadoras de valor desde as fontes de matérias-primas básicas, passando por fornecedores de componentes e até o produto final entregue nas mãos do consumidor.

Segundo Porter (1989, p.31), “a cadeia de valores desagrega uma empresa nas suas atividades de relevância estratégica para que se possa compreender o comportamento dos custos e as fontes existentes e potenciais de diferenciação."

Para Rocha e Borinelli (2006) a cadeia de valor é uma sequiência de atividades que se inicia com a origem dos recursos e vai até o descarte do produto pelo último consumidor. Os autores justificam essa definição afirmando que a definição estende o conceito desde a origem primeira dos recursos até o último consumidor, pois muitas vezes os bens são passados adiante após o ciclo de vida útil econômica nas mãos de cada usuário, reciclador, etc. antes de serem destruídos. Além disso, é importante que a definição considere todos os recursos em geral: materiais, humanos, tecnológicos e informacionais.

Assim para os autores, conforme Figura 03, Porter precisaria incluir para finalizar a análise da cadeia de valor, o consumo final do produto ou serviço. E, para iniciá-la precisaria incluir as origens de recursos para a produção do produto ou serviço.

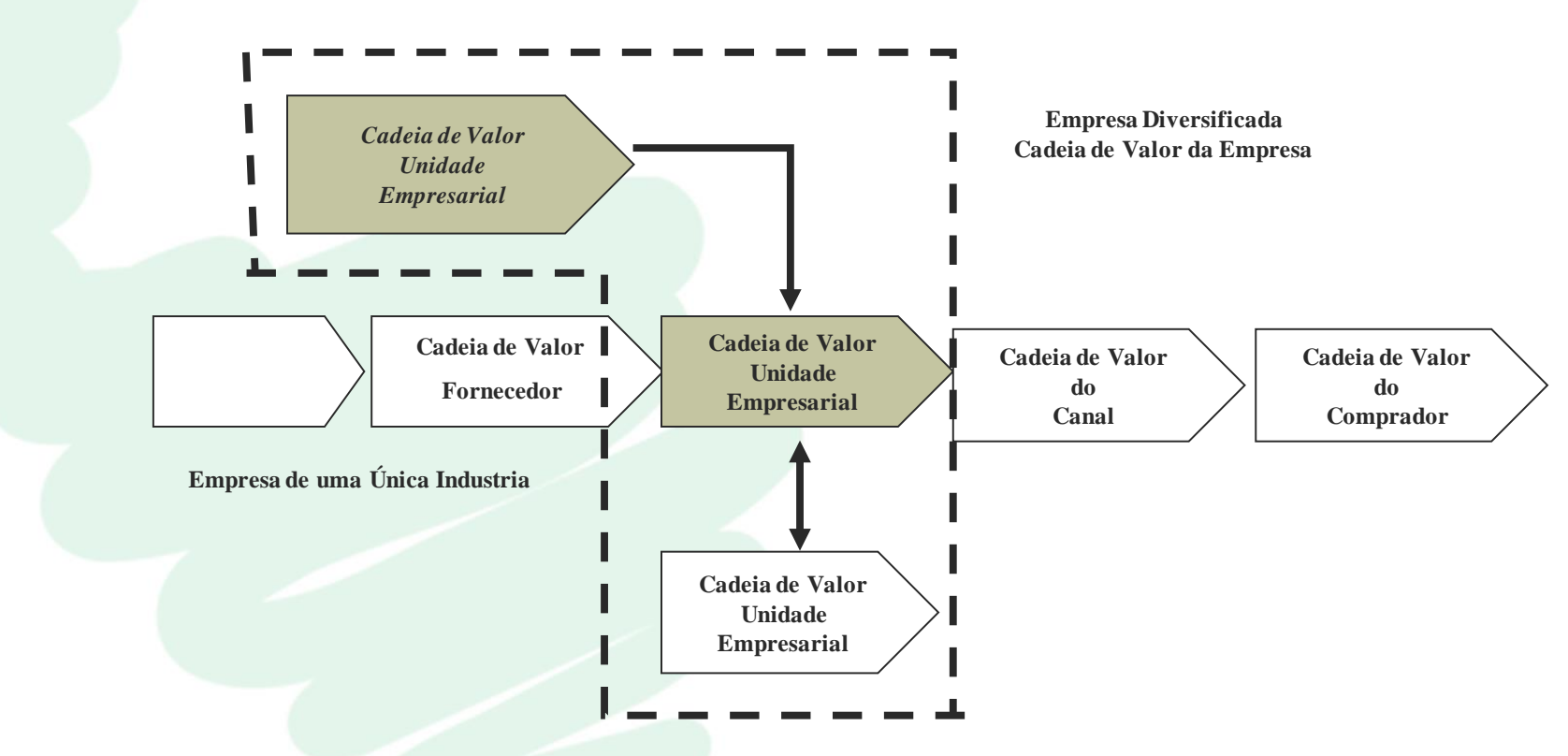

Figura 3 - Cadeia de Valores na Industria

Fonte: adaptado de Porter (1989, p.33)

Segundo Johnson et al. (1999), cadeias de produção ("supply chains") são integradas por vários participantes entrando e conduzindo acordos mutuamente benéficos de longo prazo. Tais acordos são conhecidos por vários nomes: parcerias; alianças estratégicas; terceirizações e; contratos logísticos. Outro termo relacionado com o assunto é o das redes ("networks").

Para avaliar a estrutura organizacional, Porter (1989, p. 55) ensina que a cadeia de valores oferece uma forma sistemática de dividir uma empresa em suas atividades distintas, podendo, assim, ser utilizada para examinar como são as atividades em uma empresa, e como poderiam ser agrupadas. As estratégias das empresas poderiam estar direcionadas para "Diferenciação" com propósito de distinguir a separação de atividades, e direcionadas em estratégias de "Integração" com a finalidade de coordenação de atividades.

De acordo com Kaplan e Norton (1997) cada organização usa um conjunto específico de processos, de acordo com a Figura 04, a fim de criar valor para os clientes e produzir resultados financeiros. 


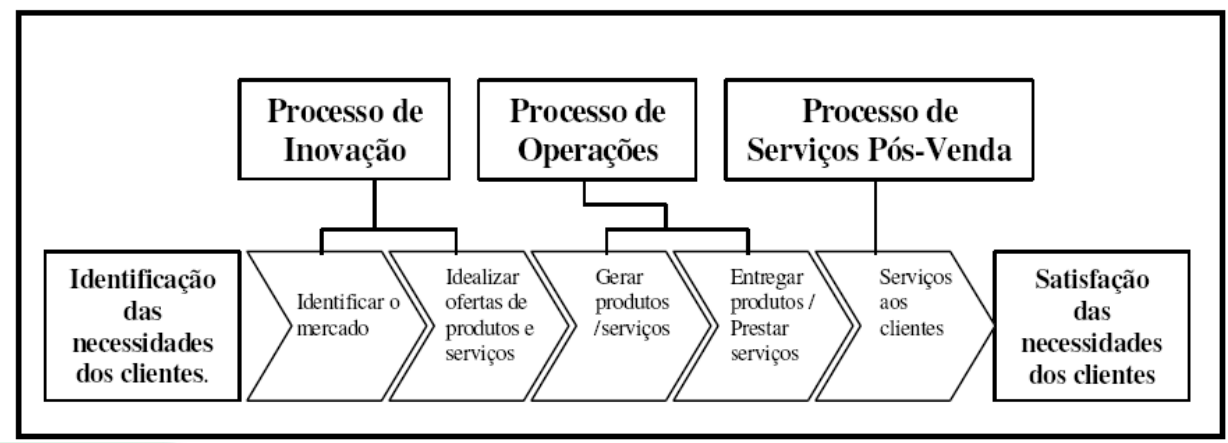

Figura 4 - Conjunto de Processos - Foco nos Clientes Fonte: Kaplan e Norton (1997)

Diante dos estudos orientados por Porter (1989, p. 55) observou-se que a cadeia de valores oferece uma forma sistemática de dividir uma empresa em suas atividades distintas, podendo, assim, ser utilizada para examinar como são as atividades em uma empresa, e como poderiam ser agrupadas.

Embora as atividades de valor sejam os blocos de construção da vantagem competitiva, a cadeia de valores não é uma coleção de atividades independentes, e sim um sistema de atividades interdependentes. As atividades de valor estão relacionadas por meio de elos dentro da cadeia de valores.

Os elos, ensina Porter (1989, p. 45), são as relações entre o modo como uma atividade de valor é executada e o custo ou o desempenho de uma outra, a habilidade para coordenar elos reduz o custo ou aumenta a diferenciação. Assim ao avaliar a cadeia de valores das empresas também analisa-se as atividades seus custos e o desempenho.

Os elos entre atividades de valor surgem quando: a mesma função pode ser desempenhada de formas diferentes; o custo ou desempenho de atividades diretas é melhorado através de maiores esforços em atividades indiretas; atividades executadas dentro de uma empresa reduzem a necessidade de demonstrar, explicar ou prestar assistência técnica a um produto no campo, funções de garantia da qualidade podem ser desempenhadas de formas diferentes.

$\mathrm{Na}$ cadeia de valores existem elos verticais os quais existem não só dentro da cadeia de valores de uma empresa, mas também entre a cadeia de uma empresa e as cadeias de valores dos fornecedores e dos canais.

Os relacionamentos das atividades da cadeia de valores de uma empresa realizadas com seus fornecedores e clientes, para Hansen e Mowen (2001, p.435), denominam-se de ligações externas, já as ligações internas ocorrem quando os relacionamentos entre atividades executadas dentro da cadeia de valores da empresa.

A origem da diferenciação de uma empresa está na forma como sua cadeia de valores relaciona-se à cadeia de seu comprador. Assim, a afirmação de Porter (1989, p. 48) “"[...] o produto de uma empresa representa um insumo comprado para a cadeia do comprador." Comprova a necessidade de avaliar também a cadeia de valores até o consumo final dos produtos ou serviços dos seus clientes.

Existem com base na literatura desenvolvida por Porter (1989) quatro dimensões do escopo competitivo que afetam a cadeia de valores: Escopo do Segmento, Escopo Vertical, Escopo Geográfico, Escopo da Indústria.

No escopo do segmento atividades de valor são compartilhadas, faz-se necessário avaliar as diferenças nas necessidades para atender diferentes segmentos de produtos. Quando apresenta diferenças entre segmentos denomina-se de escopo estreito, o escopo é amplo quando ocorrem inter-relações entre as cadeias de valores.

Diz-se que o escopo competitivo de uma empresa é vertical quando apresenta uma divisão de atividades entre uma empresa e seus fornecedores, canais e compradores, a empresa apresenta diferenciação quando consegue assumir um maior número de atividades do comprador. Dependendo da empresa e da atividade envolvida pode apresentar redução ou aumento dos custos pela integração.

O escopo geográfico permite que uma empresa compartilhe ou coordene atividades de valor empregadas para atender diferentes áreas geográficas. Inter-relações geográficas podem intensificar a vantagem competitiva se o compartilhamento ou a coordenação de atividades de valor para reduzir o custo.

O escopo da indústria apresenta Sistema logístico compartilhado, possui características semelhantes ao escopo geográfico, Nem todas interrelações resultam em vantagem competitiva. 


\section{ESTRATÉGIA COMPETITIVA}

O mercado concorrente relaciona-se ao sucesso ou fracasso das empresas determinando a adequação das atividades as quais contribuem para o desempenho das firmas. Porter (1989) aponta duas questões centrais que norteiam a escolha da estratégia competitiva pelas empresas:

- A atratividade em termos de rentabilidade a longo prazo e seus fatores determinantes;

- Os determinantes da posição competitiva relativa dentro de uma industria.
Porter (1989, p. 10) ensina: "A base fundamental do desempenho acima da média a longo prazo é a vantagem competitiva sustentável". De acordo com o autor há dois tipos básicos para as empresas atingirem um diferencial competitivo a diferenciação e ou baixo custo. Os dois tipos básicos combinados com o escopo de atividades levam a três estratégias genéricas, visualizadas na Figura 05, para alcançar um desempenho acima da média: liderança de custo, diferenciação e enfoque.

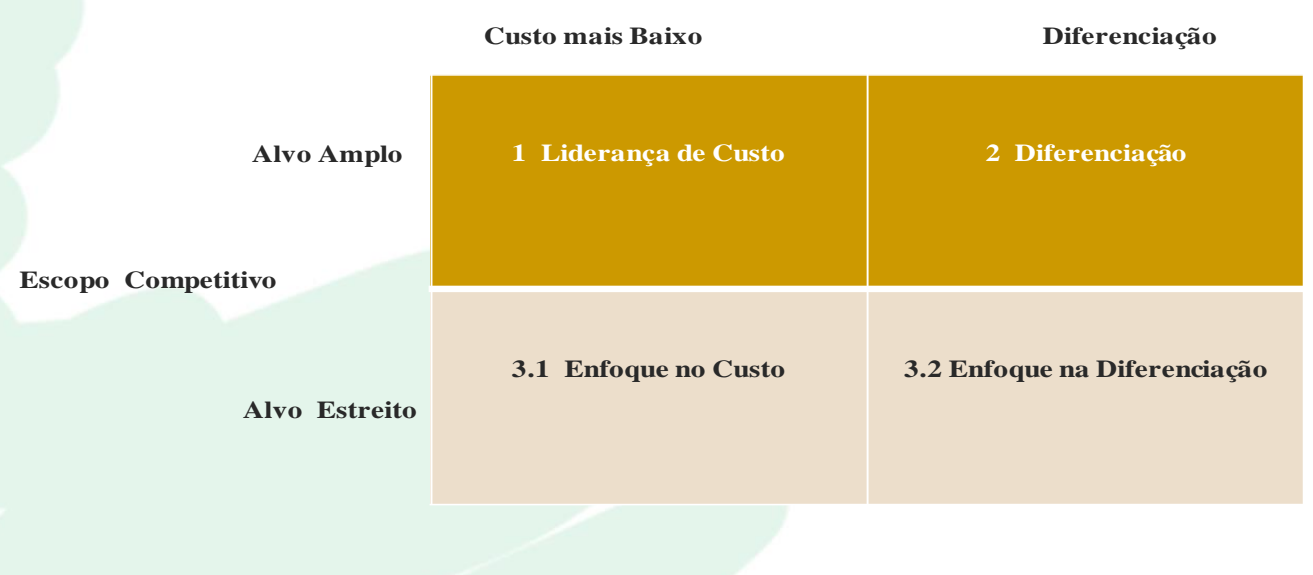

Figura 5 - Estratégias Genéricas

Fonte: adaptado de Porter (1989, p. 10)

A obtenção de uma posição de vantagem competitiva é essencial para as empresas no escopo da estratégia competitiva. E somente faz sentido em um contexto de competição. Ela é conseqüência de uma vantagem em recursos e causa de desempenho financeiro superior (ROSSI; SILVA, 2009).

Silva e Balbino (2013) explicam que no que diz respeito aos padrões que devem ser considerados pelas organizações e que influenciam diretamente o comportamento e a adaptação delas no mercado, a estratégia da organização deve ser formulada e aplicada analisando-se o ambiente externo, o ambiente interno, as atividades operacionais e o desempenho, visto que o objetivo desejado é o alcance de resultados superiores aos da concorrência. E, assim coaduna com o exposto por Dalla, Gonçalves e Muniz (2009), referente aos elementos do processo de formulação da estratégia das quais apontam a análise do entendimento do macroambiente (Econômico, Demográfico, Tecnológico, Natural, Sócio-Cultural e Político-Legal) e microambiente (Fornecedores, Clientes, Concorrentes), externos à organização, com o intuito de identificar sua vantagem competitiva e conhecer bem o setor e os concorrentes.

\section{GESTÃo DE CUSTOS E CADEIA DE VALORES}

O enfoque da análise da cadeia de valor, em contraste, é externo à empresa e vê cada empresa no contexto da cadeia global das atividades geradoras de valor. Shank e Govindarajan (1997, p. 111)

Para Miranda et al (2001), A aplicação do conceito de gerenciamento de cadeias de produção tem três características principais:

- Identifica a fonte de vantagens competitivas sustentáveis (atividades com propriedade de acesso a recursos escassos);

- Enfatiza as conexões complexas e interrelacionamentos entre os elos da cadeia (otimização conjunta versus otimização individualizada e coordenação para aumentar competitividade); e

- A formulação de estratégias genéricas (liderança por custo, diferenciação e foco/nicho de mercado).

Rocha e Borinelli (2006) afirmam que a análise da Cadeia de Valor ajuda a fornecer subsídios 
para o processo de formulação de estratégias e tem por objetivos:

a) detectar oportunidades e ameaças;

b) identificar estágios fortes e fracos;

c) detectar oportunidades de diferenciação;

d) identificar os principais determinantes de custos;

e) localizar oportunidades de redução de custos;

f) comparar com a cadeia de valor dos concorrentes etc.

Assim, os autores concluem que a análise de Cadeias de Valor serve para subsidiar o processo de gerenciamento estratégico, pois permite compreender e agir sobre a estrutura patrimonial, econômica, financeira e operacional das suas principais atividades, processos e entidades. O objetivo maior é conquistar e manter vantagem competitiva.

A metodologia da análise de cadeia de valor ensinam Shank e Govindarajan (1997, p. 72) envolve três procedimentos elementares:

- Identificar a cadeia de valor do setor e atribuir custos, receitas e ativos a cada atividade;

- Diagnosticar os direcionadores de custos que regulam cada atividade de valor;

- Desenvolver vantagem competitiva sustentável através do melhor controle dos direcionadores de custos em relação aos concorrentes ou re-configurando a cadeia de valor.

Conforme ensinam Shank e Govindarajan o método para a análise da cadeia envolve quatro pontos específicos:

- $\quad$ elos com fornecedores objetivando a interação para beneficiar toda a cadeia de suprimento;

- elos com clientes visando explorar e melhorar as relações com os canais de distribuição;

- elos das atividades internas com o propósito de otimizar os processos e as atividades internas;

- elos das unidades de negócio da empresa visando otimizar as unidades de negócio.

Rocha e Borinelli (2006) afirmam que o processo de análise de Cadeias de Valor possui as seguintes etapas:

a) Delimitar o segmento relevante objeto da análise e gestão;

b) Identificar as atividades relevantes que integram o segmento escolhido; c) Identificar as entidades que realizam as atividades relevantes;

d) Identificar as informações necessárias à tomada de decisão;

e) Elaborar relatórios que reportem as conclusões da análise.

Com relação aos dados a serem coletados, Rocha (1999, p.103-111) citado por Rocha e Borinelli (2006) propõe que, para as principais entidades de um segmento relevante da cadeia, sejam identificados:

a) a missão, as principais características do modelo de gestão e o posicionamento

b) estratégico;

c) a amplitude da linha de produtos, as dimensões das instalações e a capacidade

d) ociosa;

e) a estrutura de custos, gastos com pesquisas, programas de qualidade e de

f) preservação ambiental.

Conclui-se que a contabilidade Gerencial na análise do valor agregado precisa ultrapassar o conceito das "quatro paredes", e um dos mecanismos que poderia contribuir para isso seria a análise da cadeia de valores procurando orientar as firmas a produzirem vantagem competitiva sustentável.

\section{PROCEDIMENTOS METODOLÓGICOS}

A metodologia da pesquisa utilizada foi caracterizada como estudo empírico-analítico, realizado por meio de coleta, observação e análise dos dados. Na conceituação de Martins (2000, p.26): "São abordagens que apresentam em comum a utilização de técnicas de coleta, tratamento e análise de dados marcadamente quantitativos. Privilegiam estudos práticos."

$\mathrm{Na}$ sequência são relatados os tipos de pesquisa utilizados quanto ao objetivo, aos procedimentos e à abordagem do problema.

Dessa forma, buscando atingir o objetivo proposto, esta pesquisa caracteriza-se, como uma pesquisa descritiva. Levanta a relação existente entre a fundamentação teórica e a utilização de Cadeia de Valores na gestão de custos, junto às cooperativas agropecuárias do Estado do Paraná.

Quanto ao procedimento Gil (1999, p.65), ressalta que "o elemento mais importante para a identificação de um delineamento é o procedimento adotado para a coleta de dados".

Assim de acordo com o objetivo proposto, utilizou-se a pesquisa de levantamento ou survey, pois 
segundo Gil (1999, p.70) caracteriza-se pela interrogação direta das pessoas cujo comportamento se deseja conhecer e, em seguida, mediante análise quantitativa, obter as conclusões correspondentes aos dados coletados.
A população da pesquisa compreende 76 cooperativas no segmento agropecuário das 230 cooperativas estabelecidas no Paraná registradas no sistema da OCEPAR, conforme Quadro 01:

\begin{tabular}{|lc|}
\hline \multicolumn{1}{|c|}{ RAMO } & № COOPERATIVAS \\
\hline Agropecuário & 76 \\
Crédito & 67 \\
Consumo & 1 \\
Educacional & 14 \\
Habitacional & 1 \\
Infra-estrtura & 8 \\
Saúde & 33 \\
Trabalho & 14 \\
Transporte & 14 \\
Turismo e lazer & 2 \\
TOTAL & 230 \\
\hline
\end{tabular}

Quadro 1 - Cooperativas Paranaenses

Fonte: dados da pesquisa - www.ocepar.org.br acessado em 04.05.2007

$\mathrm{Na}$ seleção da amostra optou-se pelo tipo senso. Sendo que das empresas, o contato não foi possível com 6 devido ainda não possuir correio eletrônico disponível no site da OCEPAR e 11 delas o $e$-mail retornou como incorreto, assim o tamanho da amostra tornou-se então de 59 cooperativas agropecuárias.

Dos 59 questionários enviados por correio eletrônico, 16 retornaram com as respostas, Outras 43 não responderam ao questionário. Portanto, da população inicial de 76 cooperativas, um total de 16 , ou seja, 21,05\%, responderam ao questionário. Significa que as 16 cooperativas integrantes desta pesquisa representam a amostra por acessibilidade investigada.

O questionário foi estruturado com perguntas fechadas. Contudo antes de enviar o instrumento de pesquisa foi realizado o pré-teste do questionário recebendo contribuições principalmente quanto ao entendimento das terminologias empregadas, próprias do setor. Os respondentes dos questionários correspondem ao nível mínimo de gerentes das cooperativas, principalmente controladores, devido contato firmado anteriormente em outras duas pesquisas sendo uma referente ao perfil dos controllers das cooperativas agropecuárias do Paraná e outra referente a centros de responsabilidade, preço de transferência e avaliação de desempenho.

O questionário mestre foi elaborado em planilha eletrônica excel, os retornos foram unificados para, em seguida, iniciar-se a análise e interpretação dos dados da pesquisa utilizando a abordagem quantitativa. Richardson (1989, p. 29) explica que ela se caracteriza pelo "emprego da quantificação tanto nas modalidades de coleta de informações, quanto no tratamento dessas através de técnicas estatísticas". A técnica utilizada foi estatística descritiva em percentuais.

\section{ANÁLISES EM COOPERATIVAS AGROPECUÁRIAS PARANAENSES}

\subsection{Cooperativismo no Estado do Paraná}

Baseado na doutrina e filosofia cooperativista internacional e agrupando mais de 403 mil associados, o cooperativismo paranaense tem suas raízes nos pioneiros esforços cooperativistas nas comunidades de imigrantes europeus, que procuraram organizar suas estruturas de compra e venda em comum, alem de suprir suas necessidades de consumo, eletrificação rural e crédito através de sociedades cooperativistas.

Com seu desenvolvimento, as cooperativas passaram a ser importantes instrumentos de difusão de tecnologias e implementadoras, agindo também como elo de ligação entre o produtor rural e o governo. $\mathrm{O}$ Paraná passou à liderança nacional de produção e produtividade agrícola, transformando as cooperativas em agentes de desenvolvimento econômico e social. As cooperativas são, em muitos municípios do Paraná, as mais importantes empresas econômicas, maiores 
empregadoras e geradoras de receitas, atuando em perfeita sintonia com a coletividade, atendendo cerca de $1 / 3$ da população rural do Estado.

A vocação agropecuária do Paraná oferece potencial para o desenvolvimento do setor agroindustrial, face à disponibilidade de matériasprimas, de energia, à infra-estrutura para escoamento da produção, à proximidade aos grandes centros de consumo e pela capacidade empreendedora de seu povo.
Em 02 de abril de 1971, foi criada a Organização das Cooperativas do Estado do Paraná (OCEPAR), por decisão de 34 cooperativas paranaenses, como entidade de representação políticas cooperativistas paranaenses, que tem hoje em seus registros 230 cooperativas registradas, das quais 76 do ramo agropecuário, inseridas em vários municípios do estado do Paraná, da seguinte maneira:

Gráfico 1 - Percentual das cooperativas por região Fonte: dados elaborados pelos autores.

\subsection{Análises e resultados}

Neste tópico foram apresentadas as análises dos 16 questionários recebidos em devolução das cooperativas que integraram a amostra selecionada.

Os primeiros dados analisados nos questionários relacionam-se ao perfil do respondente ou gestor, sendo levantadas as informações relativas a faixa etária, função desempenhada e tempo na cooperativa, bem como a formação acadêmica dos pesquisados. Dos entrevistados respondentes, 13 são do sexo masculino e 3 do sexo feminino. A idade predominante ficou entre os 40 e 50 anos, com um percentual de 50\%. Na sequiência de faixa etária predominou-se entre os 30 e 40 anos, com $37,5 \%$ e entre os 50 a 60 e acima de 60 anos, com $6,25 \%$ cada opção.

Direcionados à análise das funções exercidas pelos respondentes, foi solicitado que assinalassem o nível/posição de seu cargo na estrutura organizacional da empresa. O gestor deveria assinalar entre as opções dos níveis de: cooperado, cooperado-administrador, gerente, diretor, contador, controller, ou informar outra posição não contemplada nas respostas fechadas. Os resultados são apresentados na Tabela 01:

Tabela 1 - Função dos respondentes na cooperativa

\begin{tabular}{|l|c|c|}
\hline \multicolumn{1}{|c|}{ FUNÇÃO } & RESPOSTAS & \% \\
\hline Gerente & 6 & $37,5 \%$ \\
\hline Controller & 5 & $31,25 \%$ \\
\hline Contador & 3 & $18,75 \%$ \\
\hline Diretor & 2 & $12,5 \%$ \\
\hline Total & $\mathbf{1 6}$ & $\mathbf{1 0 0 \%}$ \\
\hline
\end{tabular}

Fonte: dados elaborados pelos autores.

Com o intento de verificar a formação acadêmica dos gestores, foi solicitado aos participantes da pesquisa que informassem a sua formação. As repostas mostram que há gestores somente com formação técnica em contabilidade, alguns com superior incompleto e a maioria com superior completo, como pode ser observado no Gráfico 02: 


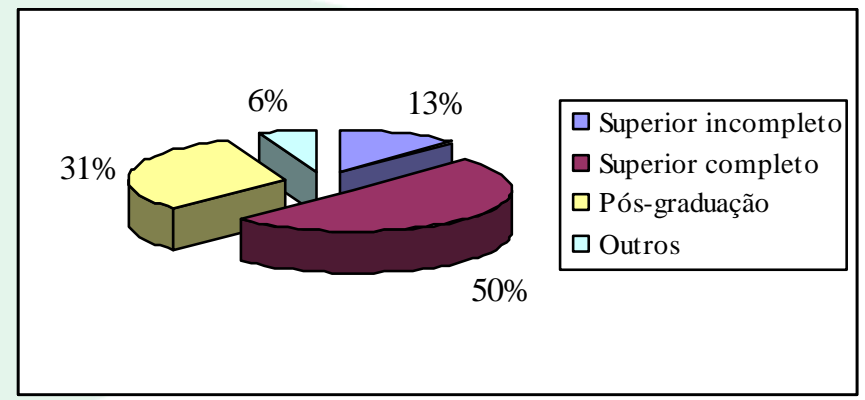

Gráfico 2 - Grau de instrução dos gestores

Fonte: dados elaborados pelos autores.

Por meio do gráfico observa-se que dos respondentes, $50 \%$ possuem formação superior completa, $31 \%$ pós-graduação, $13 \%$ superior incompleto e $6 \%$ formação a nível técnica. Dos 13 gestores com formação superior, ou seja, $50 \%$ graduados e $31 \%$ pós-graduados, os principais cursos desenvolvidos são observados na Tabela 02:

Tabela 2 - Formação acadêmica

\begin{tabular}{|l|c|c|}
\hline \multicolumn{1}{|c|}{ FORMAÇÃO } & RESPOSTAS & \% \\
\hline Graduação Ciências Contábeis & 4 & $30,7 \%$ \\
\hline Graduação Administração & 2 & $15,3 \%$ \\
\hline Graduação Economia & 1 & $7,8 \%$ \\
\hline Graduação Direito & 1 & $7,8 \%$ \\
\hline Especialização na área contábil & 2 & $15,3 \%$ \\
\hline Especialização na área financeira & 1 & $7,8 \%$ \\
\hline MBA & 2 & $15,3 \%$ \\
\hline Total & $\mathbf{1 3}$ & $\mathbf{1 0 0 \%}$ \\
\hline
\end{tabular}

Fonte: dados elaborados pelos autores

A sequência das informações solicitadas na pesquisa foi direcionada aos aspectos específicos das cooperativas agropecuárias com a finalidade de análise de suas cadeias de valores, bem como alguns pontos necessários à verificação estratégica das mesmas. A média de tempo de existência das 16 cooperativas respondentes totalizou 40,5 anos, evidenciando as estruturas sustentáveis e contínuas das organizações, devido ao elevado tempo de fundação de cada uma.

Com o objetivo de analisar as estratégias competitivas das cooperativas agropecuárias, foi solicitada a frequência de reuniões para debater o tema entre os componentes das organizações. Os resultados são observados na Tabela 3:

Tabela 3 - Periodicidade de reuniões estratégico-competitivas

\begin{tabular}{|l|c|c|}
\hline \multicolumn{1}{|c|}{ PERIODICIDADE } & RESPOSTAS & $\%$ \\
\hline Mensalmente & 8 & $50 \%$ \\
\hline Trimestralmente & 4 & $25 \%$ \\
\hline Semestralmente & 2 & $12,5 \%$ \\
\hline Outros & 2 & $12,5 \%$ \\
\hline Total & $\mathbf{1 6}$ & $\mathbf{1 0 0 \%}$ \\
\hline
\end{tabular}

Fonte: dados elaborados pelos autores

Das 16 cooperativas respondentes, 8 realizam reuniões mensais sobre as estratégias competitivas da empresa, 4 realizam reuniões trimestrais, 2 semestrais e 2 cooperativas afirmaram que realizam as reuniões apenas quando necessário. Quando solicitado quem são os responsáveis que participam diretamente no desenvolvimento das estratégias competitivas das 
cooperativas agropecuárias, foram relacionadas as seguintes funções, conforme a Tabela 04:

Tabela 4 - Participantes do desenvolvimento das estratégias competitivas

\begin{tabular}{|l|c|c|}
\hline \multicolumn{1}{|c|}{ FUNÇÕES } & RESPOSTAS & $\%$ \\
\hline Diretores & 16 & $100 \%$ \\
\hline Gerentes & 12 & $75 \%$ \\
\hline Cooperados & 8 & $50 \%$ \\
\hline Contadores & 4 & $25 \%$ \\
\hline Controllers & 4 & $25 \%$ \\
\hline Chefes de Departamentos & 4 & $25 \%$ \\
\hline
\end{tabular}

Fonte: dados elaborados pelos autores

Em $100 \%$ das cooperativas analisadas os diretores participam do desenvolvimento das estratégias competitivas, em $75 \%$ das mesmas os gerentes participam e em $50 \%$ os cooperados. Apenas em $25 \%$ das cooperativas os contadores, controllers e chefes de departamentos auxiliam nas decisões verificadas.

Ainda em relação às estratégias competitivas, na avaliação da posição das cooperativas agropecuárias paranaenses em relação à concorrência, foram enumeradas alguns instrumentos passíveis de utilização: reuniões das empresas do ramo, periódicos especializados, pesquisas técnicas, consultoria, sindicatos/federações, fornecedores, clientes e outros instrumentos auxiliares à avaliação. A Tabela 05 descreve em percentuais as opções escolhidas pelas 16 empresas respondentes:

Tabela 5 - Instrumentos utilizados na avaliação de concorrência

\begin{tabular}{|l|c|c|}
\hline \multicolumn{1}{|c|}{ FUNÇÕES } & RESPOSTAS & \% \\
\hline Pesquisas técnicas & 13 & $81 \%$ \\
\hline Sindicatos e Federações & 12 & $75 \%$ \\
\hline Reuniões das empresas do ramo & 9 & $56 \%$ \\
\hline Periódicos especializados & 8 & $50 \%$ \\
\hline Consultoria & 6 & $37,5 \%$ \\
\hline Fornecedores & 4 & $25 \%$ \\
\hline Clientes & 3 & $19 \%$ \\
\hline
\end{tabular}

Fonte: dados elaborados pelos autores

Conforme analisado, é evidente a maior utilização de informações relativas à pesquisas técnicas (81\%), dados de sindicatos e federações (75\%) e reuniões com empresas no próprio ramo (56\%) para a avaliação das posições de cada sindicato em relação aos concorrentes. As informações com utilização inferior são as de fornecedores (25\%) e clientes (19\%).
$\mathrm{Na}$ etapa de análise de cadeia de valores das cooperativas agropecuárias paranaenses participantes da pesquisa, questionou-se a forma de avaliação da mesma em cada empresa, conforme Gráfico 03: 


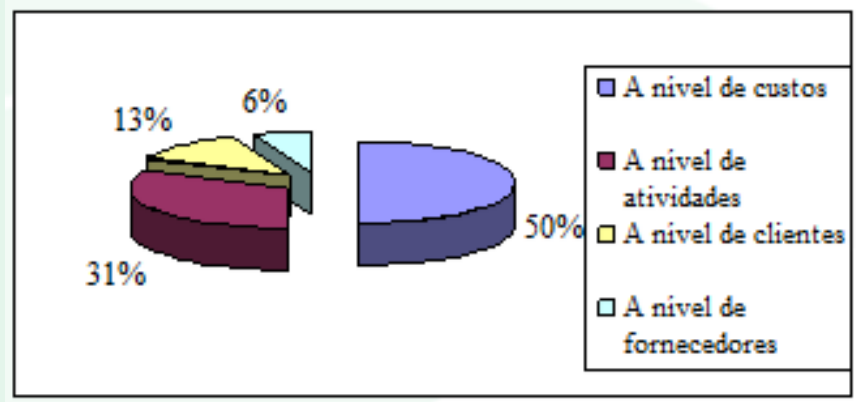

Gráfico 3 - Avaliação da Cadeia de Valores

Fonte: dados elaborados pelos autores.

Das 16 cooperativas respondentes, 8 responderam que a avaliação da cadeia de valores é desenvolvida a nível de custos, ou seja, as informações relativas aos custos da empresa são mais relevantes às tomadas de decisões, 5 responderam que avaliam a nível de atividades ou centros de responsabilidade, 2 a nível de clientes e 1 a nível de fornecedores. Destaca-se que esses resultados coadunam com os apontamentos de Porter (1989) de que a diferenciação em custos faz parte do planejamento estratégico das organizações como uma atividade elementar para promover a melhoria do desempenho das empresas. Entre os itens componentes da cadeia de valor de cada cooperativa, foram identificados conforme a Tabela 06 :

Tabela 6 - Composição da cadeia de valores das cooperativas

\begin{tabular}{|l|c|c|}
\hline \multicolumn{1}{|c|}{ FUNÇÕES } & RESPOSTAS & \% \\
\hline Fornecedores de matéria-prima & 16 & $100 \%$ \\
\hline Logística de entrada de produtos & 16 & $100 \%$ \\
\hline Logística de saída de produtos & 16 & $100 \%$ \\
\hline Serviços pós-vendas & 13 & $81 \%$ \\
\hline Vendas aos clientes & 9 & $56 \%$ \\
\hline Operações com produtos & 7 & $44 \%$ \\
\hline
\end{tabular}

Fonte: dados elaborados pelos autores

De acordo com as respostas, a cadeia de valores das cooperativas agropecuárias paranaenses inicia-se na aquisição de matéria-prima juntos aos fornecedores, compõem-se de logística de entrada e saída de produtos e finaliza-se nos serviços pós-vendas, ou seja, na manutenção dos produtos comercializados, ou seja está alinhada com a Cadeia de Valores Genérica primária, proposta por Porter (1989).

Sobre a gestão dos custos, as 16 cooperativas respondentes foram questionadas quanto à apuração dos mesmos por departamentos ou atividades. As opções disponíveis no questionário foram: o não conhecimento dos custos por departamento, a não existência de cálculo de custos, a apuração parcial por departamentos, a existência de modo não estruturado e a existência de apuração estruturada dos custos. Das empresas pesquisadas, $75 \%$ responderam que possuem apuração estruturada dos custos e $25 \%$ que possuem de forma não estruturada, totalizando as 16 respostas. Dessa forma a literatura indica que o gerenciamento de cadeias de produção apresentaram forte suporte nas estratégias genéricas de liderança por custo, diferenciação e foco/nicho de mercado (MIRANDA et al., 2001).

Quando questionados sobre as ferramentas disponíveis ao processamento das informações sobre os custos das empresas, as 12 cooperativas que possuem apuração de forma estruturada, a fazem por meio de softwares específicos. As 4 cooperativas que possuem apuração dos custos não estruturada, a fazem por meio de planilhas eletrônicas.

\subsection{Informações relevantes às cooperativas agropecuárias}

Como parte final das questões solicitadas para a presente pesquisa, foi solicitada a classificação, por ordem de importância, aos gestores respondentes sobre as informações relevantes às tomadas de decisões estratégico-competitivas componentes da cadeia de 
valores de cada cooperativa. Para tanto, utilizou-se escala Likert de 4 pontos, classificados como: 1) não é importante; 2) pouco importante; 3) importante; 4) muito importante.
A estrutura foi constituída por 12 itens a serem julgados pelos respondentes. A Tabela 07 relaciona os resultados, bem como a ordem dos itens verificados:

Tabela 7 - Grau de relevância das informações

\begin{tabular}{|l|c|c|c|c|}
\hline \multirow{2}{*}{\multicolumn{1}{|c|}{ ITENS }} & \multicolumn{4}{c|}{ ESCALA LIKERT DE } \\
\cline { 2 - 5 } & 1 & 2 & 3 & 4 \\
\cline { 2 - 5 } & - & - & - & $100 \%$ \\
\hline Informação de clientes & - & - & $25 \%$ & $75 \%$ \\
\hline Informação de fornecedores & - & - & $19 \%$ & $81 \%$ \\
\hline Informação de funcionários & - & $6 \%$ & $25 \%$ & $69 \%$ \\
\hline Informação de concorrentes & - & - & $69 \%$ & $31 \%$ \\
\hline Informação de sindicatos & - & - & - & $100 \%$ \\
\hline Informação da OCEPAR & - & - & $44 \%$ & $56 \%$ \\
\hline Informação de consultores & - & $6 \%$ & $44 \%$ & $50 \%$ \\
\hline Informação de contadores & - & $38 \%$ & $38 \%$ & $24 \%$ \\
\hline Informação da internet & - & $12 \%$ & $76 \%$ & $12 \%$ \\
\hline Informações dos governos & - & $25 \%$ & $56 \%$ & $19 \%$ \\
\hline Informações de periódicos & - & - & $12 \%$ & $88 \%$ \\
\hline Informações de pesquisas & & & & \\
\hline
\end{tabular}

Fonte: dados elaborados pelos autores

Conforme os itens verificados, nenhum obteve classificação grau 1 da escala Likert como não importante. As informações extraídas dos clientes, bem como as informações geradas pela OCEPAR Organização das Cooperativas do Estado do Paraná, foram classificadas com o grau máximo de importância. Informações de fornecedores, funcionários, concorrentes e de institutos de pesquisas também receberam maior grau de importância. Entre os outros itens analisados, verifica-se a classificação no grau 3 como importantes às estratégias competitivas das cooperativas.

\section{CONSIDERAÇÕES FINAIS}

As firmas sofrem constantes mudanças e transformações a fim de se adaptarem ao mercado nos dias atuais, atuam geralmente em cenários competitivos em que, cada vez mais os consumidores são exigentes, o mercado é volátil, alguns recursos são escassos, as empresas ineficientes e não eficazes volatizam-se.

O ambiente hipercompetitivo oriundo das mudanças contínuas nos hábitos, valores e parâmetros de gestão das empresas vêm despertando demandas de estratégias que produzam competitividade.

A literatura recomenda às empresas envolverem seus colaboradores em atividades estratégias criadoras de valores e diferenciais competitivos e assim estas atividades podem contribuir para a posição dos custos e também criam uma base para a diferenciação de estratégias. Cada organização possui uma cadeia de valores específica, ou seja, a seqüência de atividades criadoras de bens ou serviços próprios.

Essa pesquisa objetivou analisar estrategicamente quais os componentes da cadeia de valor são identificados pelas cooperativas agropecuárias do Estado do Paraná, bem como efetuar revisão bibliográfica acerca do tema.

Para corroborar com o problema e objetivo, os dados da pesquisa foram obtidos por meio de questionário enviado via e-mail. Das 76 empresas, o contato não foi possível com 6 devido ainda não possuir correio eletrônico disponível no site da OCEPAR e 11 delas o $e$-mail retornou como incorreto, assim o tamanho da amostra tornou-se então de 59 cooperativas agropecuárias. Dos 59 questionários enviados por correio eletrônico 16 retornaram, portanto da população inicial de 76 cooperativas, um total de 16 , ou seja, $21,05 \%$, responderam ao questionário.

A pesquisa survey, embora limitada pelo número dos questionários respondidos, constatou que a minoria das respondentes utilizam na avaliação da concorrência informações de fornecedores (25\%) e clientes (19\%).

A literatura indica que há dois tipos básicos para as empresas atingirem um diferencial competitivo a diferenciação e ou baixo custo. Os dois tipos básicos combinados com o escopo de atividades levam a três estratégias genéricas para alcançar um desempenho acima da média: liderança de custo, diferenciação e enfoque.

A pesquisa identificou para a análise de cadeia de valores a forma mais utilizada com um índice de $50 \%$ dos respondentes foi a nível de custos. As informações relativas aos custos da empresa são mais 
relevantes às tomadas de decisões ou seja existe predominância de $50 \%$ das respondentes quanto a preocupação de obter liderança de custo isto é o enfoque em custo.

As menores preocupações nas tomadas de decisão foi identificada na pesquisa a nível de clientes e de fornecedores, sendo $13 \%$ para clientes e $6 \%$ para os fornecedores. Comprovando assim que na análise da cadeia de valores proposta pela literatura as respondentes não possuem como foco principal a análise dos elos com fornecedores e do elos com clientes esse resultado pode caracterizar-se como uma necessidade de aprimoramento da inter-relação existente entre a proposta emanada da análise de Cadeia de Valor e a da criação de valor para fornecedores, clientes podendo assim alcançar vantagens competitivas como sugerido pela teoria.

Com essa questão pode-se perceber que a literatura preconiza a implantação de métodos para a análise da cadeia envolvendo pontos específicos dos elos sugerindo análise dos: elos com fornecedores objetivando a interação para beneficiar toda a cadeia de suprimento; elos com clientes visando explorar e melhorar as relações com os canais de distribuição; elos das atividades internas com o propósito de otimizar os processos e as atividades internas; elos das unidades de negócio da empresa visando otimizar as unidades de negócio.

Contudo a realidade difere da orientação literária, das 16 respondentes somente duas utilizam análise a nível de clientes, uma a nível de fornecedores 5 caracterizamos como elos das unidades de negócio e oito elos das atividades internas.

Quanto ao problema de pesquisa: Qual a análise estratégica de cadeia de valores na gestão dos custos para o cooperativismo agropecuário do estado do Paraná?

Considerando as limitações da pesquisa, podese constatar para a análise estratégica de cadeia de valores na gestão dos custos para o cooperativismo agropecuário do estado do Paraná tende a predominar uma análise a nível de custos, as informações relativas aos custos da empresa são considerados mais relevantes às tomadas de decisões ou seja existe predominância das respondentes quanto a preocupação de obter liderança de custo isto é o enfoque está direcionado aos custos.

Com o questionamento sobre a classificação, por ordem de importância, referente as informações relevantes às tomadas de decisões estratégicocompetitivas componentes da cadeia de valores de cada cooperativa pôde-se constatar que a ligação entre as diferentes atividades das cooperativas agropecuárias, inicia-se na aquisição das matérias-primas, até a manutenção pós-vendas dos produtos por elas desenvolvidos. Com isso, as diferentes estratégias na gestão de custos dessas empresas, se consideradas na análise estratégica dos custos podem resultar na vantagem competitiva de mercado.

\section{REFERÊNCIAS}

Atkinson, A. A.; Banker, R. D.; Kaplan, R. S.; Young, S. M. Contabilidade Gerencial. São Paulo: Atlas, 2000 .

Dalla, W. D.; Gonçalves, C. A.; Muniz, R. M. O pensamento do estrategista: fatores que asseguram a tomada de decisões estratégicas nas pequenas e médias empresas. Revista Ibero-Americana de Estratégia - RIAE, São Paulo, v. 8, n. 2, p. 80-106, jul./dez. 2009.

Hansen, D. R.; Mowen, M. M.. Gestão de Custos: contabilidade e controle. São Paulo: Pioneira Thomson Learning, 2001.

Horngren, C. T.; Foster, G.; Datar, S. M. Contabilidade de Custos. 11 ed. Rio de Janeiro: Pearson, 2004.

Johnson, J. C.; Wood, D. F.; Wardlow, D. L.; Murphy, P. R. Contemporary logistics. New Jersey: Prentice-Hall, Inc., 1999.

Kaplan, R. S.; Norton, D. P. A Estratégia em Ação. 2. ed. Rio de Janeiro: Campus, 1997.

Martins, E. Contabilidade de Custos. 9 ed. São Paulo: Atlas, 2003.

Miranda L. C. Olhando para Fora da Empresa: Combinando "Balanced Scorecard" com "Supply Chain Management" para Considerar o Fornecedor na Medição de Desempenho. ENANPAD, 2001.

Porter, M. E. Vantagem Competitiva: criando e sustentando um desempenho superior. Rio de Janeiro: Campus, 1989.

Porter, M. E. Competição: estratégias competitivas essenciais. 14. ed. Rio de Janeiro: Elsevier, 1999.

Rocha, W.; Borinelli, M. L. Análise estratégica de cadeia de valor: um estudo exploratório do segmento indústria-varejo. $6^{\circ}$ Congresso USP Controladoria e Contabilidade. Universidade de São Paulo, 2006.

Rossi, R.M.; Silva, A.L. Vantagem competitiva: operacionalizando o conceito a partir da resourceadvantage theory. Revista Ibero-Americana de Estratégia - RIAE, São Paulo, v. 8, n. 2, p. 31-57, jul./dez. 2009. 
Shank, J. K.; Govindarajan, V. A Revolução dos Custos. 2. ed. Rio de Janeiro: Campus, 1997.

Silva, M.E.; Balbino, D.P. Criando vantagem competitiva sustentável: a responsabilidade socioambiental empresarial à luz da visão baseada em recursos. Revista Ibero-Americana de Estratégia
- RIAE, São Paulo, v. 12, n. 1, p. 29-53, jan./mar. 2013.

Vieira, V.; Machado, R. K.; Brey, N. K.; Rossetto, C. R. evidências das pesquisas que abordam a tipologia de Miles E Snow no brasil. Revista IberoAmericana de Estratégia - RIAE, São Paulo, v. 11, n. 2, p. 70-90, mai./ago. 2012. 